\title{
Educação e Etnociência: caminhos da agenda 2030 para o desenvolvimento sustentável
}

Na tentativa de contornar os erros e valorizar as conquistas dos Objetivos de Desenvolvimento do Milênio (ODM's) anteriores, a ONU institu a Agenda 2030, a qual propõe 17 Objetivos do Desenvolvimento Sustentável (ODS's). A educação ambiental e a etnociência são disciplinas capazes de instituir valores culturais e reaproximar o homem da natureza. O objetivo do trabalho é identificar a relação entre os ODS's que dizem respeito à educação e à integração das comunidades através de sua ligação com os princípios da etnociência. Como resultado, foram identificadas três abordagens combinadas na educação para a sustentabilidade, necessárias à consecução da Agenda 2030.

Palavras-chave: Agenda 2030; Desenvolvimento Sustentável; Etnociência.

\section{Education and Ethnosciences: agenda 2030 pathways towards sustainable}

\begin{abstract}
In an attempt of correcting the mistakes made with the Millenium Development Goals (MDG), while still valuing its achievements, the UN proposed the agenda 2030 and its 17 Sustainable Development Goals (SDG). Education and ethnosciences are key elements in this process, once they can enable the transmission of invariable cultural values, and foster the rehabilitation of a better relationship between mankind and its environment. Hence they can drive people towards a path of sustainability. This paper aims to identify the relationship between education and communities involved on the SDGs regarding the connection with ethnosciences principles.
\end{abstract}

Keywords: Agenda 2030; Sustainable Development; Ethnoscience

Topic: Educação Ambiental

Reviewed anonymously in the process of blind peer.
Received: 06/11/2016

Approved: 10/01/2017
Isaac Newton Lucena Fernandes de Queiroz Universidade Federal do Rio Grande do Norte, Brasil. http://lattes.cnpq.br/4250755233295990

isaac4@gmail.com

laskara Michelly de Medeiros Silveira

Universidade Federal do Rio Grande do Norte, Brasil. http://lattes.cnpq.br/2533544735454556

iaskarasilveira@hotmail.com

\section{Alexandre Henrique Garcia Rego}

Universidade Federal do Rio Grande do Norte, Brasil http://lattes.cnpq.br/6700330110287264

alexandrehgr@gmail.com
Sueli Aparecida Moreira

Universidade Federal do Rio Grande do Norte, Brasil.

http://lattes.cnpq.br/9469781068838287

suelimoreira@yahoo.com.br
Referencing this:

QUEIROZ, I. N. L. F.; SILVEIRA, I. M. M.; REGO, A. H. G.; MOREIRA, S. A. Educação e Etnociência: caminhos da agenda 2030 para o desenvolvimento sustentável. Revista Ibero-Americana de Ciências Ambientais, v.8, n.2, p.250-262, 2017. DOI: http://doi.org/10.6008/SPC2179-6858.2017.002.0020 


\section{INTRODUÇÃO}

Em setembro de 2015, 193 Chefes de Estado de representação mundial tomaram assento na 70a Assembleia Geral da Organização das Nações Unidas (ONU), naquele que é o seu mais importante órgão representativo e deliberativo, para debater temas de interesse global. Dentre os temas da ordem do dia, para além dos mais diversos e constituintes problemas deste século, estava a Agenda 2030, previamente acordada na Cúpula das Nações Unidas sobre o Desenvolvimento Sustentável, realizada dias antes.

Desde que o Relatório Brundtland, datado de agosto de 1987, foi divulgado pela ONU, o conceito do termo "Desenvolvimento Sustentável" pouco se alterou. Para o documento, "a humanidade tem a habilidade de promover um desenvolvimento sustentável para assegurar que este alcance as necessidades da presente geração sem comprometer a habilidade das gerações futuras de prover as suas próprias necessidades" (UN, 1987).

Os documentos seguintes trataram o tema de forma similar. Os grandes pactos globais que se seguiram adotaram essa premissa básica, contudo, incluíram diversos outros elementos que deveriam ser discutidos no intuito de se chegar a uma proposta de desenvolvimento inclusiva e abrangente. Assim é que para os Objetivos do Milênio (ODM's), também promovidos pela ONU e lançados em setembro de 2000, por exemplo, "a promoção da igualdade de gênero e o empoderamento feminino são maneiras efetivas para combater a pobreza, a fome e a doença, estimulando um desenvolvimento que seja verdadeiramente sustentável” (UN, 2000).

A Agenda 2030, por sua vez, propõe 17 Objetivos de Desenvolvimento Sustentável (ODS's), subdivididos em 169 metas, as quais suplantaram os Objetivos de Desenvolvimento do Milênio (ODM's), desde o início do ano de 2016. De acordo com a Declaração que a inaugura, seus objetivos contemplam as inter-relações sociais, econômicas e ambientais. As metas contemplam as seguintes diretrizes:

Acabar com a pobreza e a fome em todos os lugares; combater as desigualdades dentro e entre os países; construir sociedades pacíficas, justas e inclusivas; proteger os direitos humanos e promover a igualdade de gênero e o empoderamento das mulheres e meninas; e assegurar a proteção duradoura do planeta e seus recursos naturais. Resolvemos também criar condições para um crescimento sustentável, inclusivo e economicamente sustentado, prosperidade compartilhada e trabalho decente para todos, tendo em conta os diferentes níveis de desenvolvimento e capacidades nacionais (ONU, 2015).

Em suma, os ODS's são uma extensão dos ODM's, abordando a sustentabilidade nas suas esferas econômica, social e ambiental, mas com um pool de novas prioridades para fazer frente aos novos desafios da atualidade.

Desafios esses que não são poucos. Em um momento em que se vivencia uma crise prolongada do capitalismo financeiro que arrasta os países, reduzindo a qualidade de vida de pessoas em seus aspectos físicos e emocionais, ao mesmo passo em que tensões sociais, guerra e o terrorismo globalizam os efeitos da exclusão social. Tentativas de aplacar o sofrimento, que persiste e resiste de maneira conjuntural, especialmente quando se fala de igualdade de gêneros, terrorismo e extremismo, crises humanitárias e do suplício dos refugiados pelas guerras, pelos desastres ambientais e pela mudança climática (ONU, 2015). 
Visto assim, o hoje mais parece uma reedição de um mundo dantesco e arcaico, onde a opulência oprime com vigor os pobres e excluídos; onde em um mundo cibernético, a distância entre os homens parece ser paradoxalmente cada vez maior.

Esse panorama foi inclusive tema do reconhecimento expresso das nações na Declaração da Agenda 2030. Perduram desigualdades alarmantes que, dentro dos países e entre eles, ameaçam a estabilidade e a segurança global e, por consequência, a sustentabilidade. A desigualdade que deixa os últimos por último (WATKINS, 2014) foi a principal barreira para a implementação dos ODM's em toda a parte. Até mesmo os resultados traduzidos em avanços nos cumprimentos globais dos Objetivos pelas nações continuam a ser minados pela clivagem da desigualdade de renda dentro dos países.

Chegado ao fim da Década das Nações Unidas da Educação para o Desenvolvimento Sustentável (2005-2015), a educação se reforça cada vez mais como ferramenta essencial para alcançar o desenvolvimento sustentável, dependendo da sua abordagem. Existe aqui inclusive um paradoxo, pois estudos mostram que países cuja população tem em média seis anos de estudo não conseguem desenvolver mais que uma sociedade agrária ou extrativa; por outro lado, países desenvolvidos com uma população educada são os maiores responsáveis pela grande parte dos problemas ambientais de hoje (HOPKINS, 1999). Estes últimos têm sido incapazes de solucionar as desigualdades dentro de suas próprias fronteiras. Ou seja, à medida que a educação é a chave para o desenvolvimento, é impossível negligenciar o papel da ciência e da tecnologia na gestação da crise socioambiental global, pois que enquanto ligadas à ética do regime econômico, traduzem-se em elementos de dominação e ampliação das desigualdades (SILVEIRA e ALMEIDA, 2008).

Portanto, é primordial que a tecnologia seja reorientada para a cooperação, bem como os valores transmitidos pelos agentes educativos sejam reorientados para a sustentabilidade. É como afirma Gadotti (2000): “Numa perspectiva emancipadora da educação, a tecnologia contribui muito pouco para a emancipação dos excluídos se não for associada ao exercício da cidadania".

Além disso, é fundamental que essa educação contemple a reintegração do homem com seu meio, utilizando-se da contribuição trazida pela etnociência, desmistificando assim preconceitos e encurtando o caminho para a redução das desigualdades.

A questão que esse trabalho se propõe a responder é quais as perspectivas que a educação para a sustentabilidade oferece nesse processo de guinada na governança global a partir de três premissas: 1) fortalecimento de valores culturais invariáveis como a cooperação e a solidariedade; 2) realização de ações policêntricas fundadas na descentralização do poder; e 3) resgate da memória dos saberes tradicionais para integrar as comunidades.

O estudo sugere hipóteses combinadas para que esses novos objetivos, aqui com enfoque nos temas que contemplam as três premissas supracitadas, possam ser alçados efetivamente às agendas políticas locais, regionais e nacionais através da ação educadora. 


\section{DISCUSSÃO TEÓRICA}

\section{Os objetivos e como atingi-los}

A Agenda 2030 é um conjunto de ideias, de propostas. A importância de existir um documento como esse figurando dentre as normas do direito internacional tem uma função relevante: definir um objetivo, um caminho. É com base nisso que se sustenta a primeira premissa aqui trabalhada: o fortalecimento de valores culturais invariáveis.

Dreher (2012), afirma que encorajar objetivos modestos é o primeiro passo para o caminho em direção à sustentabilidade. Nesse sentido, medidas de curto prazo não se acreditam como valores substanciais, pois podem ser facilmente substituídas por influência da mídia, por exemplo. Medidas de longo prazo que buscam implementar um valor de mudança seriam mais eficazes e se tornariam valores culturais invariáveis.

Na mesma linha, Barbieri et al. (2010), ao discutirem propostas de gestão e centralidade da questão ambiental, afirmaram que, "quando novos valores são institucionalizados na sociedade e se tornam 'mitos' a serem seguidos em um determinado setor, as organizações respondem a essas pressões adotando esses modelos e as práticas tidas como as melhores em um dado sistema social".

O conjunto de 17 ODS's, subdivididos em 169 metas, cada um tratando de um tema específico tenente à sustentabilidade, segue esse modelo. São enunciados simples e diretos cujo conteúdo é explanado de maneira inteligível, de modo que não se dirige só aos órgãos técnicos e políticos, mas também à sociedade civil.

Considerando o panorama já exposto e a direção particular do objetivo ora proposto, qual seja, o papel da educação e da etnociência para o desenvolvimento sustentável, alguns pontos da Agenda abordam diretamente a educação como indutora necessária às mudanças propostas. O ODS de número 4 contempla as metas ligadas diretamente à educação e nela está previsto que os jovens e crianças tenham uma formação pautada no desenvolvimento sustentável para que eles possam prover um estilo de vida igualmente sustentável, concluindo que cidadãos com esses valores serão indivíduos conscientes e capazes de respeitar não só a natureza, como também a própria sociedade em que vivem.

Em resumo, a proposta é construir uma educação de qualidade e melhorar instalações físicas sensíveis às deficiências e ao gênero, que proporcionem ambientes de aprendizagem seguros e não violentos, inclusivos e eficazes. Assim espera-se que valores substanciais calcados na democracia tenham lugar na vida diária dos cidadãos em todas as partes, promovendo a redução das desigualdades ao promover a reintegração do homem com o seu meio.

A proposta central, como já dito e mostrado nos itens descritos, é que, a partir de uma nova conscientização, baseada na adoção de objetivos de simples entendimento e construídos a partir de valores culturais invariáveis - dentre eles, solidariedade e cooperação, por exemplo -, é que será possível atingir os ODS's. É o que afirma Costa (2008), ao dizer que "elementos psicossociais fundamentados na cultura influenciam significativamente a formação de comportamentos - mais agressivos ou harmônicos - em 
relação à natureza, essa ressignificação de mundo possibilita a consolidação de posturas mais harmônicas, de entendimento da necessidade de preservação da natureza".

Esse debate não é novo. Infelizmente, o componente da crise ambiental se tornou imperativo na contemporaneidade, demandando novas perspectivas na gestão e governança de praticamente todos os rincões do planeta. Entretanto, é derivativa desse debate a discussão sobre a educação para a democracia com o objetivo de garantir medidas ampliativas de justiça social, o que efetivamente combina muitos dos 17 ODS's - pode-se citar a educação inclusiva, a valorização das comunidades e a cooperação entre pessoas como exemplos dessa abordagem integrada. Nesse sentido, a UNESCO, em documento elaborado em 2006, afirmou que a educação é essencial para a transmissão de valores democráticos substantivos, ainda que sujeito a veleidades perigosas:

O sistema de representação política e o modelo de exercício de poder que a caracterizam entram, muitas vezes, em crise: a distância entre governantes e governados, a excessiva emergência nos meios de comunicação social de reações emocionais efêmeras e oportunistas, a 'política-espetáculo', tornada possível pela mediatização dos debates, até mesmo a imagem de corrupção do mundo políticos, fazem com que alguns países corram o risco de ter um 'governo de juízes' e do desencanto dos cidadãos pela coisa pública. Por outro lado, muitos países atravessam, também, uma crise nas políticas sociais que ataca os próprios fundamentos de um regime de solidariedade, que parecia poder reconciliar, democraticamente, o econômico, o político e o social, sob a égide do Estado-providências. Há, pois, que reinventar o ideal democrático ou, pelo menos, dar-lhe nova vida. (UNESCO, 2006)

A questão parece se resumir, logo, a como inserir ou estimular práticas democráticas, calcadas sobre valores culturais mais ou menos invariáveis e resistentes a ruídos, crises e interferências (ou seja, resilientes), que sejam expressivos o suficiente para lidar com a questão ambiental ao mesmo tempo em que sejam simples, apreensíveis. A educação é fundamental nesse aspecto: afinal, democracia e educação andam lado a lado, afinal, como Paulo Freire afirmava, a educação é fundamental para a construção de uma sociedade livre, pois a liberdade é o modo de ser do homem (FREIRE, 2006).

Ademais, que essas iniciativas sejam policêntricas e pluralistas, esculpidas pelos atores locais - pelos indivíduos em última instância, agentes-chave nesse processo. Pelo menos essa também é a conclusão de Almeida (2002), ao dizer:

a direção, pois, do desenvolvimento sustentável deixa de ser aquela linear, única, que assumiu o desenvolvimento dominante até nossos dias; não mais a marcha de todos em uma só direção, mas o reconhecimento e a articulação de diferentes formas de organização e demandas como base, sustentáculo a uma verdadeira sustentabilidade. [...] É preciso conceber um desenvolvimento que tenha nas prioridades sociais sua razão primeira, transformando, via participação política, excluídos e marginalizados em cidadãos.

A participação política é, então, a outra chave para a viabilidade da sustentabilidade. Uma participação calcada na descentralização do poder, sustentada por valores culturais como a cooperação e a solidariedade entre as pessoas e a sinergia entre os países.

\section{Sustentabilidade e Cooperação}

Afirma o Preâmbulo da Agenda 2030 que "Todos os países e todas as partes interessadas, atuando em parceria colaborativa, implementarão este plano" (ONU, 2015). Mas, como traduzir uma possibilidade 
efetiva no cumprimento de um plano - que tem prazo - se as nações, soberanas e independentes, possuem agendas políticas diversas, interesses multilaterais e circunstâncias específicas que favorecem ou retardam esse cumprimento?

Para trabalhar esse debate e discutir a segunda premissa desse estudo (descentralização do poder), importante trazer o pensamento de Veiga (2015) em um artigo seminal, que, ao discorrer sobre a cooperação em matéria de governança de recursos comuns e sustentabilidade, utilizou-se dos estudos da vencedora do prêmio Nobel de Economia de 2009, Elinor Ostrom, segundo o Autor:

Em suma, sustentabilidade é uma noção incompatível com a ideia de que o desastre só estaria sendo adiado, ou com qualquer tipo de dúvida sobre a real possibilidade do progresso da humanidade. Em seu âmago está uma visão de mundo dinâmica, na qual transformação e adaptação são inevitáveis, mas dependem de elevada consciência, sóbria precaução e muita responsabilidade diante dos riscos e, principalmente, das incertezas. Daí a importância crucial de um sinérgico avanço do conhecimento sobre governança global e cooperação.

Para falar dessa cooperação para a governança, Veiga cita os estudos de Ostrom afirmando que as políticas elaboradas de cima para baixo, ou seja, da escala global à escala local, não são capazes de gerar confiança suficiente para a cooperação entre os cidadãos e empresas. Apenas 'interações policêntricas', assim tidas por aquelas que distribuem responsabilidade a grupos de pequeno e médio portes que estejam ligados entre si por meio de redes de monitoramento, possuem força e capacidade de estimular a ação efetiva e, por sua vez, a cooperação. A experimentação de situações particulares por esses múltiplos agentes em múltiplos níveis pavimenta o caminho para a eleição das soluções mais convenientes após a comparação entre os resultados (VEIGA, 2015).

Conclusão similar àquela que de DeCaro et al. (2008) fizeram em seu estudo, quando utilizaram elementos da psicologia social para avaliar a perspectiva de sucesso de programas de conservação baseados em comunidades em países em desenvolvimento. Segundo os autores, os programas que promovem motivação autônoma através da concessão de autodeterminação, incluindo elementos de identidade individual e cultural e interação social não coercitiva têm maiores chances de serem bem-sucedidos que outros programas que não contemplam essas responsabilidades.

Esse parece ser o caminho adotado pela Agenda 2030 da ONU, que em sua Declaração afirma: "reconhecemos a importância das dimensões regionais e sub-regionais, a integração econômica regional e a interconexão no desenvolvimento sustentável. Quadros regionais e sub-regionais podem facilitar a tradução eficaz de políticas de desenvolvimento sustentável em ações concretas em nível nacional".

A cooperação e a solidariedade são também vistos por Milton Santos quando afirma em sua obra "Por uma outra globalização" que as técnicas atuais são referentes de possibilidades de novos usos, "fundada na redescoberta cotidiana das combinações que permitem a vida e, segundo os lugares, operam em diferentes graus de qualidade e de quantidade" (SANTOS, 2006).

Santos (2006), ainda afirma que a divisão do trabalho tende a ser dualizada em duas formas que chama de "divisão por cima", esta rígida e pautada pelo capital, pouco impregnada de Política, pois que ligada às normas rígidas do poder econômico; e "divisão por baixo", esta gerada através de novos usos de 
elementos que se pensaram hegemônicos, mas que são a expressão da solidariedade dos indivíduos exercendo verdadeira Política.

Da divisão do trabalho por cima cria-se uma solidariedade gerada de fora e dependente de vetores verticais e de relações pragmáticas frequentemente longínquas. A racionalidade é mantida à custa de normas férreas, exclusivas, implacáveis, radicais. Sem obediência cega não há eficácia. Na divisão do trabalho por baixo, o que se produz é uma solidariedade criada de dentro e dependente de vetores horizontais cimentados no território e na cultura locais. Aqui são as relações de proximidade que avultam, este é o domínio da flexibilidade tropical com a adaptabilidade extrema dos atores, uma adaptabilidade endógena. A cada movimento novo, há um novo reequilíbrio em favor da sociedade local e regulado por ela. (SANTOS, 2006)

Ou, como afirma Almeida (2002), a economia deve abandonar seu papel de instituinte do campo social e passar a ser por este instituída, concluindo que as alternativas para o futuro são escolhas que devem se dar fundamentalmente no campo da política.

A necessidade do uso das ferramentas através da cooperação entre pessoas, instituições e países está disposta em diversos trechos da Agenda 2030. A reorientação da tecnologia para a cooperação entre os povos foi inclusive tema específico do Objetivo $17^{1}$, demonstrando que o valor cultural invariável da solidariedade é fundamental para uma mudança de paradigma, seja numa perspectiva local ou global.

\section{Educação e conhecimento tradicional: chaves para a sustentabilidade na Agenda 2030}

O desenvolvimento sustentável é mais que um objetivo, é um processo que não se concretiza apenas mediante a aplicação de técnicas e programas. Por se tratar do social, envolve valores humanos como o conhecimento ou sabedoria. E é a partir do conhecimento que se chega à terceira premissa ora debatida: o resgate dos saberes para a sustentabilidade.

O termo "saber" significa, em primeira mão, ter conhecimento e consciência de alguma coisa; é apreender o objeto; é captar os fenômenos em suas diversas manifestações (SILVA et al., 2013). De acordo com Diegues et al. (2001), a etnociência "parte da linguística para estudar os saberes das populações humanas sobre os processos naturais, tentando descobrir a lógica subjacente ao conhecimento humano do mundo natural, as taxonomias e as classificações totalizadoras". Partindo desta ideia, o saber local acumulado através de relações seria um importante aliado à conservação da biodiversidade. Além disso, é importante ressaltar que a cultura tradicional deve ser igualmente preservada junto com a natureza.

Nesse contexto, a Agenda 2030, no objetivo 11, meta 11.4, diz que temos como dever "fortalecer esforços para proteger e salvaguardar o patrimônio cultural e natural do mundo". Infere, assim, a favor de

\footnotetext{
${ }^{1}$ São elas: 17.6 Melhorar a cooperação Norte-Sul, Sul-Sul e triangular regional e internacional e o acesso à ciência, tecnologia e inovação, e aumentar o compartilhamento de conhecimentos em termos mutuamente acordados, inclusive por meio de uma melhor coordenação entre os mecanismos existentes, particularmente no nível das Nações Unidas, e por meio de um mecanismo de facilitação de tecnologia global; 17.7 Promover o desenvolvimento, a transferência, a disseminação e a difusão de tecnologias ambientalmente corretas para os países em desenvolvimento, em condições favoráveis, inclusive em condições concessionais e preferenciais, conforme mutuamente acordado; e 17.8 Operacionalizar plenamente o Banco de Tecnologia e o mecanismo de capacitação em ciência, tecnologia e inovação para os países menos desenvolvidos até 2017, e aumentar o uso de tecnologias de capacitação, em particular das tecnologias de informação e comunicação.
} 
uma estratégia de preservação natural e cultural que atende às viabilidades da etnociência através do conhecimento popular transmitido através das gerações.

Mais adiante, no mesmo objetivo, na meta 11.6 , tem como alvo "até 2030 , reduzir o impacto ambiental negativo per capita das cidades, inclusive prestando especial atenção à qualidade do ar, gestão de resíduos municipais e outros". Dentro dessa perspectiva, Silva et al. (2013) mostram que "isso evidencia o grande potencial dos atores locais para a manutenção dos recursos naturais, tendo em vista a estreita relação que estas populações possuem com a natureza". Sendo assim, valorizar o saber local é ter discernimento acerca do funcionamento dessas populações tradicionais a partir das suas próprias práticas.

A etnociência com seu saber tradicional local é, portanto, uma vertente oportuna para a elaboração de estratégias de desenvolvimento sustentável como cobra a Agenda 2030. Como já se afirmou, esse desenvolvimento, mais que uma meta, é um processo e, como todo processo social, depende de valores e da formação do comportamento humano. Nesse sentido, Jacobi (2003) afirma que "a produção de conhecimento deve necessariamente contemplar as inter-relações do meio natural com o social". No objetivo 4 da agenda 2030, meta 4.7, temos como propósito:

Até 2030, garantir que todos os alunos adquiram conhecimentos e habilidades necessárias para promover o desenvolvimento sustentável, inclusive, entre outros, por meio da educação para o desenvolvimento sustentável e estilos de vida sustentáveis, direitos humanos, igualdade de gênero, promoção de uma cultura de paz e não violência, cidadania global e valorização da diversidade cultural e da contribuição da cultura para o desenvolvimento sustentável.

É, por conseguinte, a educação e, mais concretamente, a educação para a sustentabilidade que desempenhará uma função estratégica de promover a reflexão da problemática socioambiental, visto que a educação permite concebermos a nós mesmos e aos demais, já que é constante a busca pelo entendimento dos laços que nos unem. Nesse sentido, a educação aliada ao conhecimento tradicional deve ser vista como um caminho para a sustentabilidade, como aborda a UNESCO no livro "De economias verdes a sociedades verdes: compromisso da UNESCO com o desenvolvimento sustentável", propondo saídas para a problemática, afirmando que "para serem sustentáveis, as soluções devem ser locais, na forma e nos resultados. Elas devem estar de acordo com os costumes e tradições locais" (UNESCO, 2012).

O saber local como importante ferramenta para o desenvolvimento sustentável também inclui a legitimidade dos atores sociais envolvidos, como coloca Jacobi (2003) "o desafio que está colocado é o de não só reconhecer, mas estimular práticas que reforcem a autonomia e a legitimidade de atores sociais que atuam articuladamente numa perspectiva de cooperação, como é o caso de comunidades locais e ONGs". A educação não pode ser completa enquanto a questão homem-natureza existir como sendo dois elementos distintos, pois, sendo uma espécie da natureza, não há soberania nessa relação. Ao se aplicar os saberes tradicionais e, portanto, os objetivos e metas da Agenda, é possível afirmar que a ciência deve estar vinculada às necessidades sociais, como informa Loureiro (2008):

seja por meio do conhecimento das especificidades sociais em suas interfaces desenhadas na história (classes, grupos sociais, etnia, gênero, família, comunidade, região, Estado, relações de apropriação e produção etc.) que é possível entender o sentido de adequação ou não das relações sociais na natureza. 
Ou seja, mais capciosa que a pergunta "como ser sustentável?" é aquela que pode soar mais obtusa e não tão clara à primeira vista: "Por que nos tornamos insustentáveis?" De onde surge essa inadequação das relações sociais?

A modernidade, marcada pela velocidade vertiginosa das mudanças de caráter técnico, cognitivo, informacional, social e cultural, culmina em uma racionalidade que se pretende única e amparada na acumulação, na ambição, na concentração de riquezas. A uniformização de um modelo empregado à força ou por meio de processos de dominação cultural e econômica, em detrimento da diversidade, é responsável pelo desaparecimento de genes, saberes, línguas, espécies, raças. O progresso, que nada mais é que o desenvolvimento auto justificado, autocontido e autodependente, torna-se vetor da "amnésia" que suprime e extingue as memórias e os saberes milenares que possibilitaram o sucesso adaptativo e evolutivo do próprio homem aos mais diversos ambientes terrestres (TOLEDO et al., 2008).

Ancorada na contumaz diminuição do papel da Política frente ao poderio econômico, o 'desenvolvimento' usualmente elogiado e pautado exclusivamente na ciência e na tecnologia como fundamentos de um crescimento numérico de Produto Nacional Bruto, não está a serviço da superação dos problemas fundamentais da humanidade, como a devastação ambiental do planeta, fome e miséria incluídas (PORTO GONÇALVES, 2003). Na verdade, os processos de concentração de poder, exclusão social e crise ambiental não se diferem um do outro, são partes de um mesmo complexo sistema que, por não comportar apenas um fator explicativo, também não comporta uma só resposta e solução. Essa uniformização do pensamento fruto dos processos de globalização implica na extinção de saberes-chave para a adaptação e sobrevivência do homem nos mais diversos habitats.

\begin{abstract}
Há múltiplos conhecimentos práticos, saberes e fazeres, tecidos em íntimo contato com o mundo, no detalhe, conhecimentos locais, não necessariamente universalizáveis, que manejam o potencial produtivo da natureza por meio da criatividade das culturas (diversidade cultural). $O$ desperdício desses saberes de povos indígenas, de camponeses, de quilombolas, de operários e de donas de casa pelo preconceito constituinte da colonialidade do saber e do poder é parte do desafio ambiental contemporâneo. (PORTO GONÇALVES, 2003)
\end{abstract}

Veja que o Autor liga diretamente a perda dos saberes tradicionais ao desafio ambiental contemporâneo, de maneira que a etnociência se fortalece como peça chave para a consecução de objetivos que digam respeito à construção (ou reconstrução) de caminhos que levem à sustentabilidade.

Tanto é importante o conhecimento tradicional e não científico que, efetivamente, foi ele que garantiu o sucesso da empreitada do homo sapiens em adaptar-se continuamente durante os milênios, desde a sua jornada inaugural na África Oriental até os dias de hoje.

Tratam-se dos saberes, transmitidos por via oral de geração a geração e, em especial aqueles conhecimentos imprescindíveis e cruciais, por meio dos quais a espécie humana foi moldando suas relações com a natureza. Esta dimensão cognitiva, tão antiga como a espécie mesma, permitiu aos seres humanos não somente manter uma certa relação de coexistência com a natureza, senão de ir afinando-a ou aperfeiçoando-a. (TOLEDO et al., 2008)

De fato, podem-se identificar dois modos de apropriação dos ecossistemas: aquele realizado pelo método tradicional (agrário ou camponês), com uma história de 10.000 anos de aprendizado agrícola 
transmitido de geração a geração; e o modelo agroindustrial (moderno), este último imaginado, implantando e replicado pela ciência. Enquanto o primeiro preza pela apropriação em pequena escala dos recursos, empregando pouco volume de matéria e energia, o segundo preza pela eficiência da produtividade em detrimento da diversidade, utilizando diversos elementos ex situ como energia fóssil, fertilizantes, pesticidas etc. (TOLEDO et al., 2008).

O elevado - e estimulado - emprego da agroindústria, baseada na monocultura, no elevado consumo de água, energia e elementos químicos contaminantes conseguem não só esgotar os solos que se tornam pobres em poucos anos, como também são raízes da exclusão social, do desemprego no campo, do inchaço nas grandes cidades (BALSAN, 2006).

Há cada vez menos trabalho no campo enquanto as periferias das cidades se apinham de excluídos e famintos. Muito embora a quantidade de comida produzida mundialmente seja mais que suficiente para alimentar a população global, a injustiça desse processo produtivo acumulador e excludente não foi capaz de satisfazer a mais básica necessidade humana: a fome.

Tanto que em 2015, 795 milhões de pessoas não obtiveram sucesso em ingerir a quantidade mínima necessária de calorias por dia, o que representa uma a cada nove pessoas no planeta figurando no mapa da fome (FAO, 2015). Pior ainda é admitir que toda essa fome acontece em meio a um panorama de virtual segurança alimentar mundial em termos de quantidade de produção (e de excesso de desperdício).

Em suma, a complexidade das causas e efeitos que traz inúmeros benefícios a uma parcela da humanidade, relegando seus efeitos nefastos aos pobres e excluídos, é a mesma que desconectou o homem de sua memória cultural, deixando em segundo planos valores fundamentais para a vida em comunidade como a solidariedade e a cooperação. Assim, "reconhecer e recuperar a memória biocultural da humanidade é uma tarefa essencial, necessária, urgente e obrigatória. Isso permitirá a visualização, construção e a colocação em prática de uma modernidade alternativa, de uma modernidade que não destrua a tradição, senão que com ela conviva, coopere e co-evolua" (TOLEDO et al., 2008). Isso parece responder a ambas as perguntas postas no início deste tópico. Entretanto, é preciso sistematizar ações para que o discurso seja posto em prática, propostas que serão debatidas a seguir.

\section{Alternativas para a consecução das metas para a educação na Agenda 2030: um caso prático}

Watkins (2014), discutindo as bases para o combate à desigualdade, afirmou que "pouco antes de sua morte, Mahatma Gandhi ofereceu uma reflexão bastante útil que ajuda a simplificar a complexidade do debate sobre equidade: 'Relembre a face da pessoa mais fraca e mais pobre que você tenha visto e perguntese se os passos que você irá contemplar serão de algum uso para ele'". Então, as soluções que se digam plurais e democráticas devem levar em conta, obrigatoriamente, a diminuição das desigualdades (daí o termo leaving no one behind, originalmente adotado pela ONU como princípio dos ODS's).

A educação se reafirma como elemento indispensável para uma verdadeira democracia, especialmente diante de um quadro de crise das relações sociais. Sua tarefa é transformar a diversidade entre os indivíduos de uma mesma comunidade - e entre comunidades e minorias - em capital para a 
formação de espaços de identificação baseados na compreensão mútua. Dar a todos os elementos necessários ao exercício de uma cidadania consciente e ativa é fundamental para a realização - e reforço - de valores democráticos (UNESCO, 2012), como a sustentabilidade.

Desta forma, o enfrentamento da crise ambiental e a consequente realização da Agenda 2030 devem partir das três premissas ora debatidas, combinadas entre si: 1) fortalecimento, pela educação, de valores culturais invariáveis como a cooperação e a solidariedade; 1) ações policêntricas fundadas na descentralização do poder; e 3) resgate da memória dos saberes tradicionais, trabalhando-os numa perspectiva de educação para a sustentabilidade.

Assim é que as políticas deveriam resgatar o papel da solidariedade e da cooperação como valores culturais invariáveis, fazendo mostrar que a desagregação provocada pela assunção da economia como determinante social gera individualismos e desconexões do homem com seu meio.

O papel do professor é primordial, pois entrosar os alunos em um debate crítico sobre o meio ambiente, questões de gênero, de discriminação racial e de todas as outras formas de inclusão social para revigorar o papel das liberdades no combate à desigualdade e na construção de uma sociedade mais justa e sustentável.

O resgate da memória cultural das comunidades faz parte do entrosamento necessário ao fortalecimento da solidariedade no combate às desigualdades e à valorização tanto do ser humano quanto do seu habitat ecologicamente equilibrado. É a postura defendida por Costa (2008), ao dizer que quando um professor opta "a valer-se dos conhecimentos etnológicos de seus alunos, ele estará confrontando dois tipos de conhecimentos - o científico e o popular - distintos e até conflitantes em certos casos, a partir dos quais abre-se uma potencial fonte de mudança conceitual para o aprendiz sobre o mundo que o cerca".

Esses valores culturais invariáveis serão, por sua vez, fundamentais para a conquista de liberdades democráticas convertidas na participação efetiva na sociedade e na definição daquilo que se quer como seu próprio destino. É como diz um dos lemas e título do relatório final da Rio +20 , embrião da Agenda 2030: the future we want (o futuro que queremos).

A Agenda 2030 ainda está em vias de se consolidar como instrumento político a nível global. A ideia central deste trabalho é, então, ampliar o debate do papel da educação e dos conhecimentos tradicionais para a discussão da questão ambiental junto às comunidades.

\section{CONCLUSÃO}

A educação libertadora é aquela que constrói a partir dos elementos e dos contextos um pensamento crítico, só sendo efetivamente possível e realizável dentro de um espectro de liberdades individuais e democráticas garantidas pela sociedade.

Os saberes tradicionais não estão em segundo plano ou oferecem respostas de segunda classe quando comparados ao conhecimento científico. Pelo contrário, se foram capazes de resistir à modernidade e às suas ferramentas, é porque são parte inafastável da interação do homem com seu meio. Sendo assim, 
cada saber é uma ferramenta útil a ser utilizada pelo educador na sua tarefa de engendrar o pensamento crítico no aluno.

A educação é também base para a construção de um futuro rico em diversidade, em valores culturais como a solidariedade entre os indivíduos e os povos e na transformação da competitividade em cooperação. É substrato para o florescimento de uma democracia forte e verdadeira, onde as pessoas sejam mais que expectadoras, mas verdadeiras donas de seus próprios destinos. Esse é inclusive o fundamento da gestão participativa: transferir a capacidade de decidir sobre o próprio futuro e assim, através da liberdade de poder escolher, ser efetivamente livre.

A Agenda 2030 é uma condensação de ideais que, como ideias que são, sozinhas não fazem nada. A práxis de cada um (de cada indivíduo, de cada entidade, de cada governo) é que vai definir se o 'futuro que queremos' é mesmo possível, se o projeto de aliar meio ambiente, sociedade e economia pode acontecer ou não passa de uma utopia. A consecução das metas do documento da ONU vai depender do esforço coletivo no combate à desigualdade, à pobreza, à fome, e combatendo-os, promove-se a possibilidade de que as gerações que hoje vivem e as que ainda virão possam usufruir de um meio ecologicamente equilibrado.

O resgate das ligações do homem com a sua terra é imprescindível nessa batalha e a educação é o meio de transformar essa quimera em realidade. Para tanto é que os três pontos considerados essenciais nesse trabalho são inter-relacionados e interdependentes: as comunidades devem instigar a educação libertadora através da verdadeira interação entre ciência e saberes tradicionais, fortalecendo valores culturais humanos por excelência, e que junto à democracia, oferecerão respostas locais e globais para a luta contra o desafio ambiental que é também um desafio econômico e, principalmente, social.

\section{REFERÊNCIAS}

ALMEIDA, J.. A Problemática do Desenvolvimento Sustentável. in: BECKER, D. F.. Desenvolvimento sustentável: necessidade e/ou possibilidade?. 4 ed. Santa Cruz do Sul: EDUNISC, 2002. p.21-29.

BALSAN, R.. Impactos Decorrentes da Modernização da Agricultura Brasileira. Campo-Território: Revista de Geografia Agrária, v.1, n.2, p.123-151, 2006.

BARBIERI, J. C.. Inovação e Sustentabilidade: Novos Modelos e Proposições. Revista de Administração de Empresas, São Paulo, v.50, n.2, p.146-154, 2010.

COSTA, R. G. A.. Os Saberes Populares da Etnociência no Ensino das Ciências Naturais: Uma Proposta Didática para Aprendizagem Significativa. Revista Didática Sistêmica, v.8, p.162-172, 2008.

DeCARO, D.; STOKES, M.. Social-Psychological Principles of Community-Based Conservation and Conservancy Motivation: Attaining Goals within an Autonomy-Supportive Environment. Conservation Biology, v.22, n.6, p.1443-1451, 2008.

DIEGUES, A. C.; ARRUDA, R. S. V.. Saberes tradicionais e biodiversidade no Brasil. Brasília: MMA; São Paulo: USP, 2001.
DREHER, J. H.. Environmental Sustainability as a Culturally Invariant Value. Spring: 2012.

WATKINS, K.. Leaving no one behind: an agenda for equity. Lancet, v.384, p.2248-2255, p.20-27, 2014.

FAO. Food and Agriculture Organization of the United Nations. FAO Statistical Pocketbook 2015: World Food and Agriculture. Rome: FAO, 2015.

FREIRE, P.. Educação como prática da liberdade. 26 ed. Rio de Janeiro: Paz e Terra, 2006.

GADOTTI, M.. Perspectivas Atuais da Educação. São Paulo em Perspectiva, v.14, n.2, 2000.

HOPKINS, C. A.; McKEOWN, R.. Education for sustainable development. Forum for Applied Research and Public Policy, v.14, n.4, p.25-29, 1999.

JACOBI, P.. Educação ambiental, cidadania e sustentabilidade. Cadernos de Pesquisa, v.118, n.3, p.189205, 2003.

LOUREIRO, C. F. B.; CUNHA, C. C.. Educação ambiental e gestão participativa de unidades de conservação: elementos 
para se pensar a sustentabilidade democrática. Ambiente \& Sociedade, v.11, n.2, p.237-253, 2008.

ONU. Organização das Nações Unidas. Transformando Nosso Mundo: A Agenda 2030 para o Desenvolvimento Sustentável. New York: ONU, 2015.

PORTO-GONÇALVES, C. W.. A globalização da natureza e a natureza da globalização. Rio de Janeiro: Civilização Brasileira, 2012.

SANTOS, M.. Por uma Outra Globalização: do pensamento único à consciência universal. São Paulo: Record, 2001

SILVA, F. J. P.. Saberes de Populações Tradicionais: Etnociência em Processos de Bioconservação.

Contribuciones a las Ciencias Sociales, n.8, 2013.
SILVEIRA, C. A.; ALMEIDA, J.. Tecnociência, democracia e os desafios éticos das biotecnologias no Brasil. Sociologias, Porto Alegre, n.19, p.106-129, 2008.

UN. Report of the world commission on Environment and Development (Brundtland Report). $42^{\text {nd }}$ Session of the General Assembly. New York: UN, 1987.

UN. United Nations Millennium Declaration. $55^{\text {th }}$ Session of the General Assembly. New York: UN, 2000.

UNESCO. De economias verdes a sociedades verdes: compromisso da UNESCO com o desenvolvimento sustentável. Brasil: UNESCO, 2012.

UNESCO. Educação: um tesouro a descobrir. 10 ed. São Paulo: Cortez, 2006.

VEIGA, J. E.. O âmago da sustentabilidade. Revista de Estudos Avançados, v.28, n.82, p.7-23, 2014 